\title{
Mari Tanaka awarded for the 2021 Japanese Economic Association award for young female researchers sponsored by the Nippon Life Insurance Company
}

\author{
Haruko Noguchi ${ }^{1}$
}

Received: 1 September 2021 / Accepted: 1 September 2021 / Published online: 1 February 2022

(c) Japanese Economic Association 2022

Building on foundations of development economics in her 2016 Ph.D. thesis, Dr. Mari Tanaka has been publishing influential work on firm behavior and human resources with careful analysis with sophisticated theory, building a research agenda with great potential for contribution to economics. In less than 5 years after completing her doctoral thesis, she has expanded her expertise and analytical skills into a diverse and effective research agenda, which includes country analysis, study of globalization, firms' human resource management and investment, economic survey methodology, and COVID-19 policies. She has built a solid and global research network that complements and highlights her skills which we believe is a credible indication that she will become one of the leaders in her field, a distinction worthy of the award for young women researchers the Nippon Life Prize.

In her doctoral thesis, Dr. Tanaka analyzed firm behavior and human capital in developing countries using Myanmar and Bangladesh data. The first chapter of the thesis has been published as M. Tanaka (2020) "Exporting Sweatshops? Evidence from Myanmar," Review of Economics and Statistics, 102(3): 442-456. Using original data she collected herself, she showed that when firms start to export as an economy becomes open, there is improvement in working conditions of workers as a result of firms joining the global supply chain.

She has two other refereed publications. Y. Sawada, H. Nakata \& M. Tanaka (2019) "Short and Long Recall Errors in Retrospective Household Surveys: Evidence from a Developing Country," The Journal of Development Studies, 55(10): 2232-2253 identifies the bias due to recall error in retrospective surveys using a 2016 Vietnam survey and proposes a method to treat the bias. The methodology developed in this paper is expected to be applied widely by many researchers in the applied econometric field in the future. M. Tanaka, N. Bloom, J. M. David and M. Koga, 2020. "Firm Performance and Macro Forecast Accuracy," Journal of Monetary Economics. 114:26-41 explores effects of firms' forward lookingness on their

Haruko Noguchi

h.noguchi@waseda.jp

1 Hitotsubashi University, Tokyo, Japan 
performance by using GDP forecasts made by individual Japanese firms and shows that firms' ability to forecast matters. Dr. Tanaka's publication portfolio demonstrates the range of her research interest, ability and network.

Dr. Tanaka has successfully developed and expanded her knowledge of specific developing countries and analytical skills into a research agenda covering microeconometrics of firm behavior and labor economics that address micro and macro issues. We commend her contributions so far as well as the research agenda she has established that gives us good reasons to be optimistic about her future contributions to the discipline. An example of her sharp insight and speed for research is $\mathrm{K}$. Kawaguchi, N. Kodama and M. Tanaka, 2020 "Small Business under the COVID-19 Crisis: Expected Short- and Medium-Run Effects of Anti-Contagion and Economic Policies" exploiting the particularity of Japanese government Covid-19 policy due to the Olympics in 2021. In addition, Dr. Tanaka has been involved in a number of other on-going studies, including policy papers and chapters in books, that is quite impressive for someone at this early stage in her career. As another indication of her successful multi-pronged research agenda, we note that she acquired IGC Small Project Grans for further Myanmar data collection, and she is or was PI in the projects related to field experiment and institutional design on how to utilize human capital. Further, she has also participated in research on labor adjustment and the spread of "KAIZEN" in emerging economies in Southeast Asia as an associate researcher. Due to all these research activities of hers, Dr. Tanaka's policy advocacy and outreach activities in Japan and abroad are highly anticipated.

For these reasons, the committee unanimously decided to nominate Dr. Mari Tanaka as the most deserving researcher for the 2021 Japanese Economic Associationfirst award for young women researchers Nippon Life Prize.

Selection committee

Haruko Noguchi (chair), Waseda University

Reiko Aoki, Fair Trade Commission

Fumio Ohtake, Osaka University

Sagiri Kitao, The University of Tokyo

Publisher's Note Springer Nature remains neutral with regard to jurisdictional claims in published maps and institutional affiliations. 